\title{
Breve esboço da tecnologia no Brasil
}

Igor Zanoni Carneiro Leão*

\section{Introdução}

Para compreender melhor o atraso tecnológico no Brasil, no estado atual da técnica e da ciência nos países desenvolvidos, faremos uma pequena reconstituição histórica dessas atividades, partindo de alguns textos básicos. O primeiro é a coletânea organizada por Milton Vargas, História da Técnica e da Tecnologia no Brasil, um dos melhores trabalhos realizados sobre o tema e publicado pelo UNESP, em 1994, bem à beira das políticas neoliberais que incidiram fortemente sobre nossa estrutura industrial. Usaremos os textos sem citá-los um a um. A principal referência será o texto de Milton Vargas, endossado por comentários marginais que possam ser esclarecedores.

Lembremos que a nossa inserção na história moderna, a nossa invenção, se deu com a formação do capitalismo europeu no antigo sistema colonial e no império marítimo português. A ciência moderna espera ainda sua época e a tecnologia como utilização da ciência na confecção de técnicas - construção e utilização de instrumentos - era insipiente. No Brasil colonial, essas técnicas eram inicialmente a indígena, dos habitantes do litoral, centrada na cultura da mandioca, cuja importância antropológica é inestimável, principalmente na organização dessas tribos.

Depois, destacam-se as técnicas de construção de raízes medievais trazidas pelos colonizadores portugueses, mas enriquecidas com processos indígenas e africanos. Destaca-se aí o estilo barroco nas igrejas e mosteiros. Um aprendizado prático, embora possamos excetuar os chamados "padres matemáticos", jesuítas com algum ensinamento científico, principalmente de elementos das matemáticas.

Mas a indústria mais importante na Colônia é a açucareira para a qual foram indispensáveis as técnicas medievais, como energia fornecida por roda de água. Soma-se aí uma organização do trabalho de corte manufatureiro e, depois, no final do século XVIII, a introdução das caldeiras a vapor no fabrico do açúcar. Também sem nenhuma organização em corporações de ofício, a mineração, especialmente a do ouro, que não ultrapassou a técnica artesanal.

\footnotetext{
* Doutor em Economia pela UNICAMP. Professor do Departamento de Economia da UFPR. Endereço eletrônico: igorza@bol.com.br
} 
É importante acrescentar que o trabalho escravo tende a inibir o avanço técnico e, sob domínio da Contra-reforma, Portugal e Espanha entram no século XVI, abandonando a corrida rumo à práticas mais modernas de produção e pesquisa científica, o que explica parcialmente a letargia material da Colônia portuguesa, que só começa a sofrer impactos da ciência moderna no início do século XIX, com a chegada da corte portuguesa no Rio de Janeiro. Inicia-se então a implantação do ensino superior no país e o interesse pela cultura científica moderna, manifestado por profissionais liberais e militares: médicos envolvidos em ciências da natureza; advogados dedicando-se às ciências da cultura; engenheiros e militares interessados em ciências exatas. O próprio José Bonifácio, mineralogista conceituado na Europa, era interessado em problemas técnicos de mineração e metalurgia.

As expedições científicas que visitaram o Brasil, à época, além de estudar nossa natureza, também transferiram conhecimentos científicos, como conhecimentos geológicos. As escolas profissionais superiores, como as Academias naval e militar do Rio de Janeiro, seguidas de outras em São Paulo e Minas Gerais, o Jardim Botânico, o Museu Nacional e o Observatório Astronômico inauguram um aprendizado científico capaz de resolver problemas técnicos por engenheiros e militares. Destaca-se, na engenharia civil, a fundação, em 1858, da Escola Central, separada da Academia Militar, mas ainda ligada ao Ministério da Guerra. Ambas realizaram obras públicas como construção da estrada de ferro e obras portuárias.

A escola ensinava matemática, astronomia, geologia, física, química, seguidas de um curso de artes e manufaturas. Mais tarde, separam-se as engenharias civis, a mecânica, industrial e de minas.

As principais atividades no final do século XIX eram a construção de edifícios, os estudos, projetos e construção de portos e o projeto e construção de estradas de ferro, seguidas da mineração, metalurgia e indústria. Nesta última destaca-se a ação pioneira do Visconde de Mauá que, embora importante para a economia, sem relevância tecnológica, pois era baseada na importação de máquinas e na contratação de obras e técnicas estrangeiras. A maior difusão da indústria, segundo o estudioso Roberto Simonsen, deu-se a partir de 1866, na evolução das indústrias de bens-de-consumo, como alimentação, têxtil, vestuário, produtos químicos e outros.

Com a ainda recente Revolução Industrial, técnicas dispendiosas e demanda por grande massas de consumidores eram condições inexistentes num país ainda escravocrata e recém saído das malhas do regime colonial. Os primórdios da indústria no Brasil, como nota Simonsen, esperariam que as técnicas daquela Revolução Industrial se generalizassem e que a 110 
transição para o trabalho livre ocorresse criando um mercado de consumo para bens correntes, tudo isso ligado ao grande vigor da lavoura cafeeira, a princípio escravista e depois capitalista no centro-sul do Brasil.

Ao lado dessas atividades, especialmente ligada ao Exército, em todo o período colonial se instalam aulas de fortificações e artilharia, construindo fortalezas e desenvolvendo estudos científicos fundamentais em matemática, mecânica, hidráulica, física e geografia. Outras técnicas surgem Segundo Império, como a Engenharia Elétrica, com a instalação da iluminação elétrica, do telégrafo, do cabo submarino até a geração elétrica por empresas estrangeiras, até a Segunda Guerra Mundial. Todas essas obras estão ligadas à ocupação, à defesa do território e a uma infra-estrutura básica da Corte e da urbanização então incipiente.

Mais adiante, na República velha, ao lado da construção de portos ao longo da costa brasileira, como uma atividade nitidamente tecnológica, a partir dos anos 20, há também obras de saneamento, como as de Santos, a construção de estradas de rodagem, as obras contra as secas, o notável desmonte do Monte do Castelo, no Rio de Janeiro. Seguem-se as construções das primeiras hidrelétricas de grande porte, ligadas aos empreendimentos estrangeiros, já que os investimentos nacionais eram de curto alcance. Nesses anos de auge do complexo cafeeiro, primeiro fluminense, depois paulista e mineiro, surgem as primeiras empreiteiras de construção civil, em moldes industriais, com capacitação tecnológica inteiramente nacional. Surgem também as primeiras grandes pontes rodoviárias e viadutos de concreto armado com sofisticado planejamento. É interessante indicar que imperava na época o nacionalismo como reserva de mercado para empresas nacionais, que competiam arduamente por espaço econômico, requerendo proteção. Outro ponto importante é a urbanização que reclama esse tipo de atividade.

Essa tecnologia civil nos anos 20 foi motivada pelo aparecimento do concreto armado. Já em 1913 o engenheiro Paulo Souza lecionava cálculo das estruturas de concreto armado e exigia o conhecimento técnico do concreto e das barras de aço doce que o constituíam. $\mathrm{Na}$ década de 20, amplia-se a pesquisa tecnológica em várias instituições no campo dos cimentos concretos e barras de aço, bem como o de combustíveis e minérios. Logo, esses avanços dão lugar a estudos e pesquisas ligadas ao concreto de grandes massas e a geotecnologia das fundações de grandes estruturas e obras de terra. Tudo isso se acelera a partir da década de 50, quando se faz necessário investir na indústria brasileira através de um conjunto de metas de energia e transporte, dando notabilidade internacional à tecnologia civil brasileira. 
Transição similar se dá com o setor da eletricidade, quando, a partir de 50, a geração de energia elétrica no início do século, baseada no capital estrangeiro, teve de dar lugar ao avanço no ensino e na pesquisa tecnológica em material elétrico e nas companhias de geração e distribuição de energia elétrica, como condição de avanço industrial. Nesse período de rápido desenvolvimento industrial, diferenciação e aprofundamento da malha industrial e integração do espaço econômico nacional, fortemente incentivado pelos governos de Vargas e de Kubitscheck, desenvolve-se também a indústria siderúrgica, que culmina com a construção de Volta Redonda, sob a política de implantação de coque metalúrgico e exportação de minério de ferro. A tecnologia da usina foi comprada e transferida para o Brasil pelo Exército e pelo Instituto de Pesquisas Tecnológicas de São Paulo.

Desde o avanço industrial do período chamado Encilhamento até o final da Segunda Guerra, não há, a rigor, nenhum avanço de tecnologia nacional na indústria. Esse é um processo que começa nos anos 20 e tem um grande auge nos anos 50, motivado pelo governo trabalhista e populista que começa sua marcha na revolução de 30, tanto por sua intervenção em indústrias chave, como pelo incentivo ou atuação direta em órgãos estatais e empresas públicas. Mesmo na liberal República velha, porém, o café deu margem a setores industriais, com forte interesse estrangeiro, como o da química: cimento, vidros, adubos químicos, produtos farmacêuticos, produtos alimentícios, sabões, papel, tecidos, couros e explosivos.

Surgem então cursos de Engenharia Industrial e Química na Escola Politécnica de São Paulo para formação de engenheiros químicos. No Mackenzie, o curso de Química Industrial. A indústria química possuía produtos farmacêuticos, produtos alimentícios e produtos químicos, diversificando-se nos anos 30 para papel, tecidos, couro e exclusivos, rayon e outras fibras sintéticas. Em 1964 formou-se um grupo executivo para coordenar as atividades brasileiras na área, o que foi o germe dos pólos petroquímicos construídos no II PND.

Após a guerra, o ensino e a pesquisa científica se esforçam para ancorar a produção industrial e as atividades de engenharia, agora centradas nas áreas de telecomunicações, informática e fontes de energia convencionais e nucleares, com forte planejamento do desenvolvimento desejado, burocracia específica e órgãos como a CEPAL e o BNDE. Das Forças Armadas surge o Centro Tecnológico de Aeronáutica, o Centro Técnico Aeroespacial, o Instituto Militar de Engenharia e, na marinha, a promoção junto com a escola politécnica de São Paulo do curso de Engenharia Ambiental também realizado na UFRJ. Tributária desses esforços, a indústria de armamentos organiza empresas estatais como a EMBRAER, 
construindo aviões com tecnologia desenvolvida no ITA, empresas privadas como a ENGESA, para veículos blindados, eletrônica e mísseis balísticos e a AVIBRAS para produção de aviões e foguetes militares. Depois, a BERNARDINI passa a produzir, em 1973, carros de combate.

A Indústria Brasileira de material bélico foi criada em 1976 para a produção de explosivos e armas e, junto com a Helicópteros do Brasil AS (Helibrás), compõe-se o quadro de uma indústria armamentista criada com incentivos fiscais e privilégios de importação desvinculada do mercado, mas sem produção tecnológica compatível com seus propósitos.

No pós-guerra, a Telebrás interliga o território nacional por conta da tecnologia eletrônica entre 1965 e 1980. A política nacional de telecomunicações nacionalizou os equipamentos de comunicação e suas indústrias e o território nacional foi todo coberto pela Embratel, primeiro por troncos terrestres de microondas depois por satélites artificiais. Entre a década de 40 e de 80 , monta-se uma indústria eletroeletrônica de equipamentos de comunicação, quase toda instalada na Zona Franca de Manaus, além do desenvolvimento da linha de produção de fibras óticas, contando com ampla proteção governamental.

O consumo energético entre 1946 e 1986 multiplica-se por 10, embora ainda baixo pelos padrões internacionais. Mas é possível observar os efeitos do consumo de energia no desenvolvimento tecnológico industrial e no nível de vida, demonstrando a conhecida relação entre o consumo energético, o desenvolvimento econômico e o bem estar social.

A matriz de energia no início dos anos 90 incluía 32\% de energia elétrica, 36\% de petróleo e outros fósseis, 29,5\% de álcool e biomassas e 0,5\% de energia nuclear. Percebe-se a necessidade de intensificar a geração e o consumo de energia elétrica, dominar a tecnologia de projeto e construção de usinas a carvão e nucleares, intensificar a utilização do gás natural, redimensionar o Proálcool, explorar fontes alternativas e aprimorar o senso ecológico.

A indústria de informática começou com as máquinas de calcular nos anos 20 até os primeiros computadores eletrônicos construídos no Brasil, passando pela fábrica de sonar e o desenvolvimento da pesquisa eletrônica no Instituto Tecnológico da Aeronáutica. Os primeiros computadores de utilização científica, comercial ou industrial, começaram a chegar ao Brasil na década de 1920, concomitante com os Planos de Metas. Mas a Informática só avança a partir de 1970, com as Forças Armadas assumindo um papel nitidamente nacionalista, incentivando uma expansão industrial de computadores de pequeno porte, apoiando-se na massa crítica de professores, cientistas e tecnólogos brasileiros. Passou-se daí para uma fase de engenharia reversa, na qual se nota adaptações e melhorias, mas sem 
avanços significativos. Finalmente, a história da indústria nuclear brasileira é longa, complexa e marcada pela falta de coerência e da continuidade na condução na política nuclear.

A indústria nacional cresce após a segunda guerra mundial até aproximadamente 1980, dobrando seu produto real a cada seis anos, provavelmente, a maior taxa do mundo. Nos anos 80 e início dos 90, com a crise econômica, parecia haver no Brasil um "fator tecnológico" muito ligado à tecnologia importada e que por isso mesmo precisa ser desenvolvida com massa crítica nacional, por engenheiros, tecnólogos, mestres e operários especializados.

Entretanto, as tecnologias industriais, embora bem sucedidas, são em sua maioria importadas, o que se liga a sua deficiente competitividade internacional. Na há falta no país de cientistas competentes, engenheiros e operários habilidosos, mas principalmente tecnólogos, que adaptam a ciência e a engenharia aos usos técnicos. Segundo Milton Vargas, "isso comprova nossa tese de que a tecnologia não é mercadoria que se compra, mas sim saber que se aprende". Essa afirmação coloca em discussão amplos setores da política industrial tecnológica e científica, provavelmente realçando a importância que teve o crescimento econômico, o planejamento e o setor estatal para o desenvolvimento dessa tecnologia, mesmo quando privada ou estrangeira.

O livro organizado por Milton Vargas é publicado em 1994. Antes de entrar na década de 90, pensemos um pouco na década anterior. A crise da dívida que atinge o Brasil entre vários países no início dos anos oitenta fechou os mercados de crédito e obrigou a uma dura contração da atividade econômica, associado à busca de grandes superávits comerciais para saldar os juros e as amortizações da dívida externa. Isso levou a um declínio dos níveis de investimento, da produção e do emprego. Certamente, foi um período negativo para o avanço da tecnologia e da produtividade industrial. Como se sabe, há uma relação entre incremento da demanda e do investimento, estímulo às inovações e produtividade, comandada pelo que acontece no setor industrial. Segundo o texto Uma Interpretação sobre a Evolução da Produtividade Industrial no Brasil nos anos noventa e as "Leis" de Kaldor, de Carmem Aparecida Feijó e Paulo Gonzaga M. de Carvalho,

"Nos anos setenta a taxa de crescimento da produção, do emprego e conseqüentemente da produtividade, moviam-se conjuntamente, resultado de uma correlação positiva entre variação da produção e do emprego. Nos anos oitenta a produtividade industrial ficou praticamente estagnada, mas a correlação entre o crescimento da produção e do emprego ainda foi positiva." 
Portanto, embora a década de oitenta seja vulgarmente chamada década perdida, isso é parcialmente exagero porque se manteve intacto o conjunto da estrutura inicial com pequeno aumento do investimento e do emprego, que inclusive apresentou avanço na formalização do trabalho.

Nos anos noventa, no período que decorre os governos Collor e Itamar Franco, começa a se montar um conjunto de reformas ditadas pelo Consenso de Washington, como foi chamado por John Willianson, e que desembocam na estrutura dos dois governos FHC. Em primeiro lugar, no plano internacional abre-se uma possibilidade de renegociar débitos atrasados da dívida externa, com deságio, o que permite uma revalorização da dívida antiga diante de um risco de inadimplência, e por outro lado abre espaço para uma pressão em várias áreas como rápida abertura comercial, desnacionalização de empresas cujo preço despencou com a âncora cambial destinada a sustentar a inflação, privatização de diversos setores chave na economia moderna, como o de comunicações e telecomunicações, bem como possibilidade de bancos estrangeiros comprarem participação no cenário de bancos privados brasileiros. Essas mudanças foram acompanhadas até 1999 quando ocorre outra crise financeira no mercado mundial por um câmbio fixo que, ligado à abertura das importações foi vital para financiar as importações e garantir valor financeiro do real. Nesse contexto o investimento industrial é baixo, bem como são baixas as taxas de crescimento da produção e do emprego, mas a produtividade do trabalho é muito elevada, revelando ganhos de produtividade decorrentes de quedas sistemáticas no emprego industrial.

Diversos autores explicam esse caso como conseqüência de inovações na estrutura industrial, que mudou acentuadamente nos anos noventa, e nas políticas de inovação. Segundo Feijó e Carvalho, nos anos noventa a indústria cresceu mais lentamente, e o aumento da produtividade industrial não está ligado a uma eliminação de setores produtivos menos eficientes. Todavia, o impacto da estabilização de preços e da estrutura econômica alterou a estrutura industrial, com alguns setores ganhando peso e outros perdendo. Assim, perderam espaço na esfera industrial setores da cadeia têxtil-vestuário, calçado, e de metalúrgica básica, e ganharam espaço os setores químico, refinado de petróleo, máquinas e equipamentos e setores alimentares.

Perderam importância no que diz respeito à produtividade setores tradicionais de têxtil-vestuário e calçados, fumo, refinado de petróleo, fabricação de máquinas para escritório e informática, fabricação de material eletrônico e outros equipamentos de transporte. Agregando os setores segundo o grau de intensidade tecnológica ganharam peso na estrutura 
industrial setores de alta tecnologia, média-alta tecnologia e baixa tecnologia, em detrimento do setor de média-baixa tecnologia. A produtividade industrial cresceu em todos os setores ao longo dos anos noventa com queda do emprego, e com mais intensidade em setores que já tinham alto nível de produtividade.

O mercado de trabalho apresentou queda sistemática no volume de emprego, com diminuição de 13\% dos vínculos de emprego e elevação de 10,2\% do emprego formal na década, elevando as taxas de desemprego na economia e piorando a qualidade dos empregos. Assim, como dizem os autores,

"Não há como dissociar o aumento da produtividade industrial na década de noventa da queda na absorção da mão de obra. A abertura econômica, nesse sentido, provocou um enxugamento das estruturas produtivas, o que levou a contração do emprego no setor manufatureiro. Ao mesmo tempo, aumenta o grau de informalidade e cresce o desemprego. Finalmente, a boa produtividade industrial não se expressa em resultados apreciáveis no volume de exportações industriais".

É bem conhecido que a industrialização brasileira no pós-guerra até os anos noventa se deu em condições de estabilidade tecnológica a nível internacional, ocorrendo poucas exceções a isso no plano de produtos e processos. Os impasses da economia mundial destacaram por um lado inovações financeiras compondo um anel paralelo de valorização do capital e por outro uma busca acirrada e sistemática de inovações tecnológicas. Este é o quadro de um capitalismo instável sem suficientes marcos regulatórios. No caso do Brasil a industrialização contou com tecnologia internalizada, com tecnologia própria e das filiais de empresas transnacionais, prevalecendo no tecido industrial estas últimas.

Após um período de pausa nos anos oitenta, os anos noventa após o Plano Real modernizou a indústria pelo lado da oferta concentrando também setores e indústrias e privatizando ou desnacionalizando ainda mais o tecido industrial brasileiro. Nesse período, como notam Feijó e Carvalho, a indústria perdeu importância, mas garantiu um crescimento de produtividade mais elevado que os outros setores. A estrutura industrial se alterou, no entanto as Contas Nacionais não mostram diminuição de valor agregado. Além disso, os setores industriais apresentaram níveis de produtividade muito distintos, acompanhados por queda do emprego. Esse desemprego não foi absorvido pelos demais setores exceto o terciário mais pobre. Ao mesmo tempo a demanda externa tem muito menor importância que a demanda interna. Como o crescimento da demanda e da renda foi muito baixo, os autores 
concluem que o aumento de produtividade deveu-se mais a condições de oferta do que da demanda.

A partir da primeira década do século XXI no governo Lula as grandes importações deram lugar a maciças exportações graças a novos parceiros comerciais como a China e a Índia, mas isso não se traduziu em aumento da demanda interna, que foi contida por uma política monetária e fiscal muito dura e pelo câmbio sobrevalorizado pela folga de divisas e o próprio baixo crescimento. Nesse sentido o governo Lula não diferiu acentuadamente dos governos FHC. Como mostraram clássicos como Celso Furtado em todos esses anos houve continuidade da industrialização com a manutenção de dependência política e econômica perpetuando o subdesenvolvimento.

A heterogeneidade produtiva e técnica aumentou bastante após os anos oitenta e o mundo do trabalho concentrou um hiato de miséria absoluta que o bolsa família busca suportar e ao mesmo tempo não tornar explosiva. O capital brasileiro tem em como um dos seus principais componentes o agribusiness, o segundo maior produtor e exportador de commodities para o mercado mundial. Suas decisões são tomadas pelas companhias de negócio mais importantes no mundo, definindo áreas, produtos, práticas agrícolas e outras. Elas convivem com a grande massa de miseráveis do campo. As commodities industriais também estão em processo de desnacionalização e a sua vantagem que era energia abundante e barata vem se diluindo. Esses setores são os únicos que geram um saldo líquido de divisas.

Por sua vez o capital industrial a partir de 1995 foi desestruturado em suas cadeias produtivas produzindo déficits comerciais crescentes como a da eletroeletrônica e das telecomunicações. Vivem aí também as grandes exportadoras que são as indústrias de transporte, grandes indústrias com processos produtivos segmentadas pelo mundo e com intensa troca intra-industrial de peças e componentes.

Os serviços de infra-estrutura e de utilidade pública, alvos de uma privatização e de uma estrutura de regulação ineficiente, necessitam ser rearticulados desde que se retome financiamento público em infra-estrutura no mercado local. Há outros problemas ligados ao mercado monetário financeiro que vêm sendo comentados em cada número deste Boletim.

Aqui queremos destacar que a economia brasileira apresenta um efetivo potencial tecnológico desenvolvido no país, ou seja, tecnologia que se conhece e domina em poucas ilhas importantes, como a Petrobrás e a Embraer. São honrosas exceções, mas são apenas exceções. A história da industrialização brasileira do ponto de vista da tecnologia, do crescimento, do emprego e da igualdade social está por ser escrita. 


\section{Referências Bibliográficas}

VARGAS, Milton (organizador) (1994); História da Técnica e da Tecnologia no Brasil- São Paulo: Editora da Universidade Estadual Paulista: Centro Estadual de Educação Tecnológica Paula Souza, 1994

FEIJÓ, Carmem Aparecida; CARVALHO, Paulo Gonzaga M. de (2002); Uma Interpretação sobre a evolução da produtividade Industrial no Brasil nos anos Noventa e as "Leis" de Kaldor, Nova Economia, Belo Horizonte Julho/Dezembro.

TAVARES, Maria da Conceição (2001); O Subdesenvolvimento da Periferia Latino-Americana: o caso do Brasil no começo do século XXI, UFRJ. 